\title{
CONCEPTUAL FRAMEWORKS AND THEORETICAL MODELS FOR THE PSYCHOLOGICAL SELECTION OF FUTURE OFFICERS
}

\author{
Adrian PRISĂCARU \\ adrian_prisacaru@yahoo.com \\ ECOLOGICAL UNIVERSITY OF BUCHAREST, ROMANIA
}

\begin{abstract}
The objective of this paper is to present the approaches to the elaboration of psychological profiles of military forces and specialties and the choice of the theoretical model that underlies the elaboration/selection of psychological assessment tools. The theoretical models underpinning the psychological assessment activity have been extensively studied and conclusive scientific data and evidence have been obtained in empirical studies conducted over several years. For example, the multiple intelligences model, which accepts that people have different and distinct cognitive strengths and styles, highlights and takes into account the most representative psychological characteristics of the person being assessed in order to propose the most optimal match with the requirements of the military branch/specialty in which he/she can develop.
\end{abstract}

\section{KEYWORDS:}

Job analysis, psychological profile of military forces and specialties, multiple intelligences

1. Psychological characteristics of future officer between psychological requirements of the job and the individual psychological profile

Generally speaking, the psychological assessment carried out for selection purposes aims to ensure that the human resources are suitable for the tasks and activities in the military environment, taking as its essential points of reference: the psychological requirements or psychological profile of the post, hereinafter referred to as the psychological profile specific to military forces and specialities, the individual psychological profile of the person being assessed and the job description.

Although the three elements are intrinsically linked, it should be noted that in the psychological assessment stage carried out for the purpose of selecting future officers, only the psychological profile specific to military forces and specialities is used, without taking into account the job description, which contains a number of specific features of each job, the reason being that the persons assessed 
are not directly employed in a particular job but undergo a period of training specific to similar groups of jobs.

The selection activity of future officers is usually carried out in two stages, taking into account four areas (Prisăcaru \& Cracsner, 2010), as follows:

a) the preliminary stage, which is mandatory and eliminatory, includes the assessment of medical, psychological and physical fitness levels;

b) the basic stage is mandatory and includes the school/vocational or subjectspecific knowledge assessment.

Within the domains the "state" at a given moment is assessed, on the basis of which a prediction can be made of the person's health, capabilities and behaviour, significant for the military profession, as follows:

- The "medical" domain aims to assess the state of health and represents a set of clinical and paraclinical examinations for each medical specialty. They aim to determine the degree of physical development, the general state of health and functioning of different organs as well as the body as a whole. The results obtained are expressed in the Apt-Fit/Inapt-Unfit opinion for the assignment of persons to different military branches/specialities.

- The "level of physical fitness" area is concerned with the assessment of readiness for effort and motor capacity/skills, by means of endurance and skill tests involving the stressing of the muscular and skeletal system, and the result is expressed by the Pass/Fail opinion.

- The "psychological field" is aimed at assessing aptitude and structural potential, and the results of the assessment are used to draw up the individual psychological profile which, by reference to the requirements of the psychological profiles of the military branches / specialities, helps to base the psychological decision expressed in the Pass / Fail opinion.

The assessment of cognitive aptitude potential does not focus on accumulated knowledge, but on the ability to understand and work with various information, as well as the level of development of mental processes / characteristics such as: quality, mobility and speed of thought, spatial representation, technical intuition, problem solving, etc., which have implications for academic / professional performance.

With regard to the assessment of the structural potential of personality, it aims at capturing psychological characteristics called personality traits, such as emotional balance, responsibility, conscientiousness, etc., which have implications for adaptation, interpersonal relations, working under stress, leadership in groups, etc.

- The ,professional/scholastic” domain involves the assessment of general and/or specific knowledge of certain specialities, the ability to resolve situations with content specific to the branch or military speciality and the originality of the way in which they are resolved, the result being expressed in marks on a scale of 1 to 10 .

\section{Branches-specific psychological} profile and military specialities as a result of the work analysis

On the basis of the elements presented above, the following question arises: how can we know which psychological characteristics correspond to the psychological profile of each branch and military speciality used in the selection process?

The literature approaches this issue through the concept of work analysis or job analysis. Popa (2012) considers that "work analysis is a scientific way of determining the behaviours associated with a given activity, establishing their difficulty and hierarchy according to the level of importance", and Smither (as Popa, 2012), considers that "job analysis is a process of identifying the tasks and behaviours necessary to successfully fulfil the requirements of a job".

We infer that through the process of work analysis we will obtain both a list of tasks associated with the job or family of jobs, and a list of attributes or psychological 
characteristics involved in the performance of tasks, in our case of each branch and military specialty, which will lay the foundation for the design of the psychological profile specific to branches and military specialties.

In order to achieve this goal, i.e. to draw up the psychological profile specific to each military branch / speciality used for selection, a process is followed which facilitates the transition from the tasks associated with the post or family of posts to the identification of predictors of professional behaviour.

Predictors are represented by some psychological characteristics, such as verbal aptitude, technical aptitude, emotional stability, etc., which are able to predict what we want from each person evaluated, such as for example professional performance, adaptation to the organisational environment, etc. called psychological criteria.

Some authors consider that predictors are defined in terms of psychological characteristics and the instruments that assess these characteristics. Thus, Popa (2012, pp. 293-294) considers that ,psychological predictors are various individual characteristics used in order to make some judgments about a person's behaviour in various work situations. In psychological assessment for selection purposes, predictors are values resulting from the measurement of psychological characteristics of the person being assessed that have the ability to correlate with some of the psychological criteria (such as job performance)". And the psychological criteria are defined as dimensions consisting of manifest behaviours, influenced by predictors, targeting the behaviours expected from the assessed persons in terms of academic / professional adaptation and performance (Pitariu \& Albu, 1996).

With regard to the process of identifying the predictors that underlie the psychological profile of each military branch / specialty, we mention two significant steps:

- identification of the most relevant predictors, their definition and operationalisation;

- establishing the final number of predictors used in the psychological assessment for each branch and military speciality.

For the identification and selection of the most relevant predictors, it is recommended to use the model called "Fleishman's Taxonomy", which includes a number of 52 skills from the cognitive, psychomotor, physical, sensoryperceptual categories and 21 from the personality traits category, approached as social/interpersonal skills (Fleishman, 2008).

Concerning the phase of establishing the final number of predictors used in the psychological assessment for each branch and military specialty, we present a fragment of the results of a study published in 2016 (Marineanu, Prisăcaru, Georgescu \& Franga), which aimed to develop the list of predictors identified as relevant to specific professional activities, retaining a number of 30 predictors (Table no. 1 and no. 2).

Table no. 1

Mean, standard deviation and rank of the 30 predictors

\begin{tabular}{|c|l|c|c|c|}
\hline $\begin{array}{c}\text { Predictor crt. no. } \\
\text { (from list of 30) }\end{array}$ & \multicolumn{1}{|c|}{ Predictor name } & Mean & $\begin{array}{c}\text { Standard } \\
\text { deviation }\end{array}$ & Rank \\
\hline 1. & Verbal aptitude & 10.00 & 5.39 & 23 \\
\hline 2. & General learning aptitude & 18.83 & 2.92 & 7 \\
\hline 3. & Numerical aptitude & 6.83 & 4.53 & 29 \\
\hline 4. & Technical aptitude & 8.50 & 5.47 & 27 \\
\hline 5. & Spatial aptitude & 11.33 & 6.49 & 22 \\
\hline 6. & Functional aptitude & 12.58 & 9.26 & 19 \\
\hline 7. & Organisational aptitude & 19.25 & 2.84 & 3 \\
\hline 22. & Conscientiousness & 19.17 & 3.65 & 4 \\
\hline 23. & Responsibility & 19.28 & 2.44 & 2 \\
\hline 30. & Leadership potential & 19.40 & 1.18 & 1 \\
\hline
\end{tabular}


Table no. 2

Psychological profile/predictors for the infantry branch

\begin{tabular}{|c|l|c|c|c|}
\hline $\begin{array}{c}\text { Crt. } \\
\text { no. }\end{array}$ & \multicolumn{1}{|c|}{ Predictor } & Category & $\begin{array}{c}\text { Hierarchy } \\
\text { level }\end{array}$ & $\begin{array}{c}\text { Predictor } \\
\text { weight } \mathbf{( \% )}\end{array}$ \\
\hline 1. & Leadership potential & personality trait & 1 & 12 \\
\hline 2. & Responsibility & personality trait & 1 & 12 \\
\hline 3. & Organisational aptitude & cognitive aptitude & 1 & 12 \\
\hline 4. & Conscientiousness & personality trait & 2 & 7 \\
\hline 5. & Self-control & personality trait & 2 & 7 \\
\hline 6. & Adaptability & personality trait & 2 & 7 \\
\hline 7. & General learning ability & cognitive aptitude & 2 & 7 \\
\hline 8. & Self-confidence & personality trait & 2 & 7 \\
\hline 9. & Distributive attention & cognitive aptitude & 3 & 5 \\
\hline 10. & Openness & personality trait & 3 & 5 \\
\hline 11. & Emotional stability & personality trait & 3 & 5 \\
\hline 12. & Initiative & personality trait & 3 & 5 \\
\hline 13. & Activism & personality trait & 4 & 3 \\
\hline 14. & Stable/balanced disposition & personality trait & 4 & 3 \\
\hline 15. & Spirit of observation & cognitive aptitude & 4 & 3 \\
\hline
\end{tabular}

The list of 30 predictors (Table no. 1) was transformed into a tool (scale) containing all possible combinations of predictors organised in different pairs and submitted to analysis / completion by selected persons from each military branch / specialty with extensive professional experience, called experts, with the task of choosing the predictors considered most important for their branch / specialty. Subsequently, by taking into account established limits on the statistical mean, which expresses the importance of the predictor (in the range $14.50 \geq M>19.40$ ) and the standard deviation, which highlights the agreement between the evaluators (in the range $5.87<\mathrm{S}<4.16$ ), the profile shown as an example was designed (Table no. 2).

\section{The theoretical model} underpinning the assessment of cognitive skills

The measurement of intelligence, known as IQ, is a long-standing concern of specialists, using various instruments, some of them quite sophisticated, often resulting in a score and a hierarchy of individuals assessed on the basis of only one dimension.

No doubt this approach is correct and works well for some people, after all everyone is treated in the same way, but an alternative model, guided by a different orientation on intelligence measurement, is represented by the pluralist view of intelligence, a model that recognizes several discrete and different facets of cognition, which accepts that people have different cognitive powers and styles (Prisăcaru, 2012).

Such an approach is pertinently argued in the early 1980s by Howard Gardner, called "multiple intelligences theory", whereby he appreciates that it "better describes human cognitive competence in terms of a set of mental capacities, talents or aptitudes and that all people possess each of these capacities to some extent, the difference being in the proportion and nature of their combination" (Gardner, 2006). The theory pluralizes the traditional concept of intelligence, arguing that an intelligence is "a computational capacity", i.e. an ability to process a particular type of information or the ability to solve a particular type of problem based on identifiable operations or set of operations, and is activated or triggered by certain types of information present internally or externally (Gardner, 2006).

Some studies equate the concept of intelligence with that of aptitude, and 
aptitude is defined as " $a$ complex of individual psychological processes and attributes, structured in a personal way, that enable certain activities to be performed successfully" (Zlate, 2000, p. 56), while cognitive skills refer to those skills and knowledge that individuals acquire, retain in memory, combine and reuse in new situations (Humphreys, 1979).

Therefore, starting from the conclusion that military branches and specialties are characterized both by some common elements related to the psychological characteristics with implications in solving work tasks, but especially by some particular elements, which give them specificity, highlighted by the different content of the predictors in the composition of the mentioned profiles, we consider that the most appropriate way of approaching the psychological assessment aims to highlight the psychological peculiarities through the prism of the model presented above.

To this end, predictors from the category of cognitive skills wich are used for the development of assessment instruments have been defined and operationalised, with regard to: verbal skills (V.A.), spatial skills (S.A.), numerical skills (N.A.), organisational and functional skills (O.F.A.), technical skills (T.A.) and general learning skills (G.L.A.). In order to highlight the approach, we bring to attention a fragment of the results of the study (Prisăcaru, 2012), as follows:

a) spatial aptitude (S.A.) expresses the ability to determine the shape, size, relationship and orientation of an object in relation to another or to a certain structure, being necessary for deciphering the relationships between some graphic elements presented or arranged in a two- or threedimensional plane, solving concrete situations in the field, placing conventional signs on a plan of action or on a map, developing action strategies, etc.;

b) numerical aptitude (N.A.) expresses the ability to work with numbers, to quickly solve simple arithmetical problems placed in context, being necessary for the management of material and human resources, planning and time management, administration and use of budgetary funds, calculation of resource requirements and their judicious use, etc.;

c) organisational and functional aptitude (O.F.A.) expresses the ability to grasp details, accuracy in comparing, evaluating and assessing products, plans, series of letters, words, perceptual speed, speed of decision-making, required for drafting and completing documents, organising, planning and carrying out activities, transmitting messages and data by means of communication media, encrypting and decrypting coded messages, speed of decision-making in situations of constraint, etc.

After the development of items specific to each of the six cognitive skills assessment instruments, complex studies were carried out to establish the final form of the instruments, which were applied experimentally to a group of 655 participants, heterogeneous in terms of educational and professional background, age and gender.

Table no. 3 shows, as an example, some data obtained from the statistical processing of individual results for the applied instruments (Prisăcaru, 2013).

Table no. 3

Statistical mean values

\begin{tabular}{|l|c|c|c|c|c|c|c|}
\hline \multirow{2}{*}{$\begin{array}{c}\text { Military } \\
\text { branch/specialty }\end{array}$} & \multicolumn{6}{|c|}{ Aptitude: } & \multirow{2}{*}{ General score } \\
\cline { 2 - 8 } & V.A. & S.A. & N.A. & O.F.A. & T.A. & G.L.A. & \\
\hline $\begin{array}{l}\text { A.F.A. /Air Force: } \\
\text { - org. manag. } \\
\text { - pilots }\end{array}$ & 5.99 & 11.03 & 7.94 & 6.71 & 9,81 & 6.77 & 48.26 \\
\cline { 2 - 8 } & 5.44 & 10.56 & 7.00 & 6.52 & 9,96 & 6.48 & 45.96 \\
\hline
\end{tabular}




\begin{tabular}{|c|c|c|c|c|c|c|c|}
\hline \multirow{2}{*}{$\begin{array}{c}\text { Military } \\
\text { branch/specialty }\end{array}$} & \multicolumn{6}{|c|}{ Aptitude: } & \multirow{2}{*}{ General score } \\
\hline & V.A. & S.A. & N.A. & O.F.A. & T.A. & G.L.A. & \\
\hline \multirow{4}{*}{$\begin{array}{l}\text { A.F.T. /Army: } \\
\text { - org. manag. } \\
\text { - public admin. } \\
\text { - finance manag. }\end{array}$} & 5.20 & 9.46 & 6.59 & 6.27 & 8.71 & 5.57 & 41.81 \\
\hline & 5.42 & 9.76 & 7.10 & 6.18 & 9.17 & 5.89 & 43.51 \\
\hline & 4.98 & 9.19 & 5.94 & 6.38 & 8.16 & 5.08 & 39.73 \\
\hline & 4.70 & 8.57 & 6.17 & 6.43 & 8.13 & 5.78 & 39.78 \\
\hline A.F.N. / Navy & 5.46 & 9.92 & 7.54 & 6.62 & 9.92 & 6.08 & 45.54 \\
\hline Engineering & 5.96 & 10.36 & 8.71 & 6.54 & 9.91 & 6.44 & 47.93 \\
\hline Medicine & 6.08 & 6.25 & 6.17 & 6.67 & 8.25 & 5.17 & 38.58 \\
\hline \multirow{3}{*}{$\begin{array}{l}\text { Total sublot } \\
\text { Admitted sublot } \\
\text { Rejected sublot }\end{array}$} & 4.99 & 8.87 & 6.26 & 6.02 & 8.39 & 5.35 & 39.87 \\
\hline & 5.42 & 9.77 & 6.97 & 6.38 & 9.03 & 5.89 & 43.46 \\
\hline & 2.80 & 4.28 & 2.62 & 4.16 & 5.11 & 2.59 & 21.56 \\
\hline
\end{tabular}

From the data presented some conclusions can be drawn (presented fragmentarily), as follows:

- for technical specialities compared to management or logistic support specialities, the following skills stand out through the averages of the scores obtained:

- spatial aptitude (S.A.) - A.F.A., followed by engineering and then A.F.N.;

- technical aptitude (T.A.) - A.F.N., followed by engineering and then A.F.A;

- numerical aptitude (N.A.) engineering, followed by A.F.A. and then A.F.N.;

- general learning aptitude (G.L.A.) - A.F.A., followed by engineering and then A.F.N.;

- verbal aptitude (V.A.) - engineering, followed by A.F.A. and then A.F.N.

\section{The theoretical model underlying the assessment of personality traits}

In terms of designing and carrying out the psychological assessment of personality traits, the approach is greatly simplified, given that the literature clarifies many aspects of the practice, both through the diversity of published studies and conclusions, and the psychological assessment instruments developed by various authors.

A central model for approaching personality theories is the Big Five Model (McCrae \& Costa, 2008), which considers that people can be characterised by five traits: extraversion, neuroticism, agreeableness, conscientiousness and openness to novelty.
Regarding the stage of choosing instruments for psychological assessment of predictors in the category of personality traits, we would like to point out that it did not follow some complex procedures, since there is sufficient scientific evidence recommending the use of instruments designed according to the above-mentioned model, regardless of the name it bears.

In this sense, we find in the literature conclusions indicating that high conscientiousness influences exam results (Chamorro-Premuzic \& Furnham, 2003), and a low score obtained on the trait called neuroticism has positive effects on academic performance (De Feyter, Caers, Vigna \& Berings, 2012; Furnham et al., 2003). Also, Oakes et al. (2001) show that some cognitive skills and personality traits play a significant role in predicting outcomes in some training programs, and Demetriou et al. (2019) support the idea that general cognitive ability predicts academic performance at $22 \%$, followed by conscientiousness.

\section{Valuing cognitive ability assessment results}

Given the purpose of the paper, we will refer only to the activity of school / vocational orientation, which is carried out by relating the individual psychological profile to the optimal psychological profile of the military branch / specialty (Figure no. 1) (Prisăcaru, 2013). 


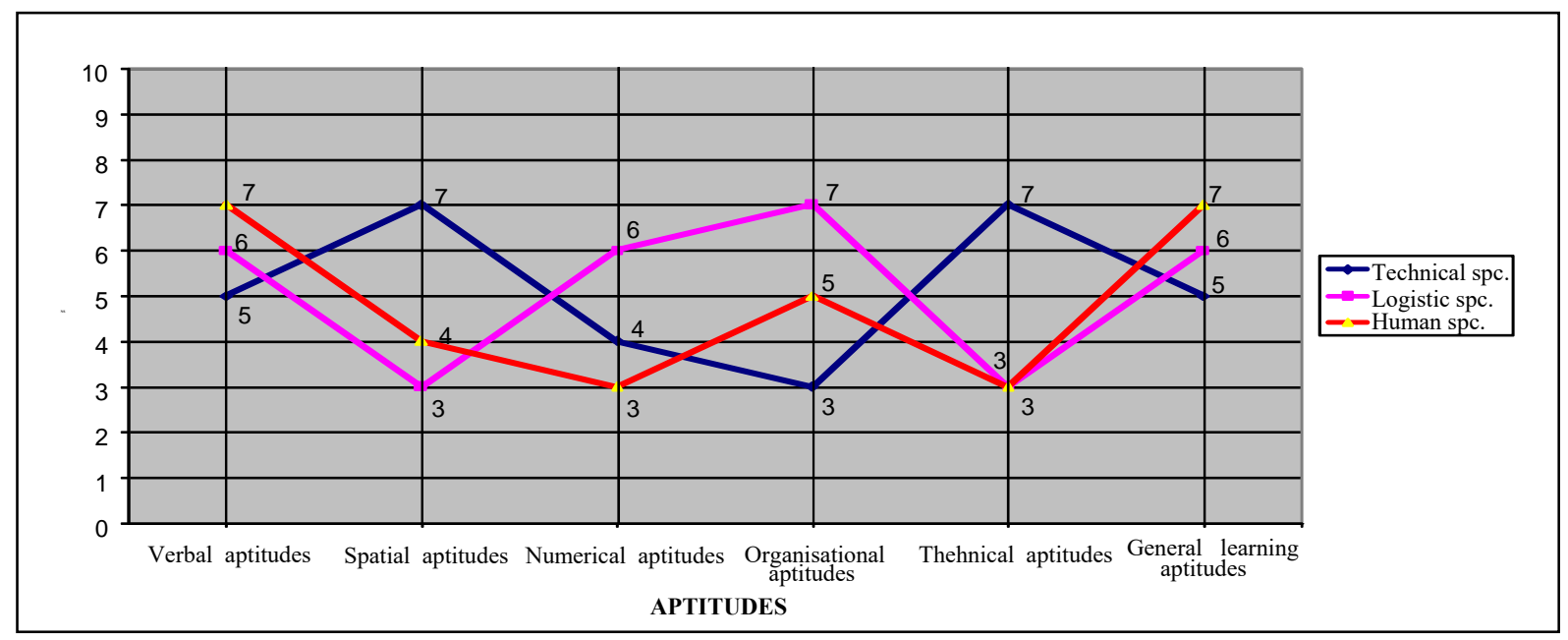

Figure no. 1: Graphical fitness profile for cognitive skills (orientative model)

For example, we analyse the results obtained by a candidate selecting a technical branch as an option in the selection process, expressed in standard scores (S.S.): verbal aptitude S.S. $=9$; spatial aptitude S.S. $=4$; numerical aptitude S.S. $=4$; organisational and functional aptitude S.S. $=8$; technical aptitude S.S. $=4$; general learning aptitude S.S. $=8$.

From the data presented, it appears that the assessed person has a set of cognitive skills developed at an uppermedium level, characterised by: the ability to understand relationships between notions and to elaborate verbal reasoning; the ability to grasp details, accuracy in comparing and appreciating products, programs, plans, series of letters, letters, words, perceptual speed, speed in decision-making, as well as the ability to receive, accumulate knowledge / information transmitted verbally or in writing and to operate with them.

At a lower level is the ability to construct reasoning based on numerical relationships, the ability to represent space in two or three dimensions and the ability to understand some principles of mechanics and physics.
The person is recommended for some branches / specialities in the logistics and humanities fields, contrary to his initial choice for a technical branch, and a recommendation will be communicated in the school/vocational guidance counselling activity.

\section{Conclusions}

We can conclude that in the psychological assessment for the selection of future officers the focus is on the predictive function, aimed at predicting performance in academic/professional work and adaptation to the organizational environment.

At the same time, we conclude that the psychological assessment is an important step in a broad approach, and that it involves obtaining scientifically validated evidence on the importance and role of some predictors in forecasting the specific potential of the persons evaluated, so as to propose the best correspondence or match between the person, through the prism of the individual psychological profile and the psychological profile of the military branch / specialty in which he / she will have the best performance and adaptation. 


\section{REFERENCES}

Chamorro-Premuzic, T., \& Furnham, A. (2003). Personality Predicts Academic Performance: Evidence from Two Longitudinal University Samples. Journal of Research in Personality, Vol. 37, Issue 4, 319-338.

De Feyter, T., Caers, R., Vigna, C., \& Berings, D. (2012). Unraveling the Impact of the Big Five Personality Traits on Academic Performance: The Moderating and Mediating Effects of Self-Efficacy and Academic Motivation. Learning and Individual Differences, Vol. 22, Issue 4, 439-448.

Demetriou, A., Kazi, S., Spanoudis, G., \& Makris, N. (2019). Predicting School Performance from Cognitive Ability, Self-Representation and Personality from Primary School to Senior High-School. Intelligence, 76.

Fleishman, E.A. (2008). Human Skills Guide. Cluj-Napoca: Sinapsis Publishing House.

Gardner, H. (2006). Multiple Intelligences. Bucharest: Sigma Publishing House.

Humphreys, L.G. (1979). The Construct of General Intelligence. Intelligence, Vol. 3, 105-120.

Marineanu, V., Prisăcaru, A., Georgescu, A.M., \& Franga, M. (2016). Methodological aspects regarding the relevance of predictors in the psychological evaluation carried out in the military organization. Bucharest: Publishing House of the Technical-Editorial Center of the Army.

Mc Crae, R.R., \& Costa, P.T. (2008). Toward a new generation of personality teories: Theoretical contexts for the five-factors model. The five-factor model of personality: Theoretical perspectives. New York: Guilford.

Oakes, D.W., Ferris, G.R., Martocchio, J.J., Buckley, M.R., \& Broach, D. (2001). Cognitive Ability and Personality Predictors of Training Program Skill Aquisition and Job Performance. Journal of Business and Psychology, Vol. 15, Issue 4, 523-548.

Pitariu, H.D., \& Albu, M. (1996). Staff psychology. Measuring and interpreting individual differences. Cluj-Napoca: Cluj University Press Publishing House.

Popa, M. (2012). Military psychology. Iaşi: Polirom Publishing House.

Prisăcaru, A. (2013). Psychological selection to joint the military system in the light of the model of multiple intelligences. Romanian Military Thinking, No. 1.

Prisăcaru, A., \& Cracsner, E.C. (2010). The facets of multiple intelligence in the theory and practice of psychological selection. Bucharest: Publishing House of the TechnicalEditorial Center of the Army.

Prisăcaru, A., (2012). The prevalence of the multiple intelligences model in psychological selection. Bucharest: Publishing House of the National Defense University.

Prisăcaru, A., Georgescu, A.M., Franga, M., \& Chițu, G., (2015). Methodological aspects regarding the evaluation of the set of psychological criteria "general skills". Bucharest: Publishing House of the Technical-Editorial Center of the Army.

Zlate, M. (2000). Introduction to psychology. Iași: Polirom Publishing House. 